\title{
OPINIÓN
}

\section{DESAFÍOS PASTORALES PARA ENTENDER Y CONFRONTAR LA REALIDAD}

Ponencia ante la Fraternidad Teológica Latinoamericana, capítulo El Salvador, 10 de febrero de 2007

\author{
Mario Vega \\ Pastor General de Misión Cristiana Elim \\ El Salvador \\ E-mail: mariovega7@gmail.com
}

Nuestro tema se divide en dos partes: el entender y el confrontar la realidad. En ambos casos, se dice que esto conlleva desafíos pastorales. ¿Por qué debe ser un desafío entender la realidad? ¿Por qué debe, igualmente, ser un desafío confrontar la realidad?

Busquemos las respuestas yendo una a una por estas dos divisiones de nuestro tema.

\section{¿Por qué es un desafío entender la realidad?}

1.1 'Porque el mundo está al revés. Donald Kraybill, en su libro' El Reino al revés ${ }^{1}$, nos confronta con la verdad que los valores del Reino de Dios son tan radicalmente diferentes a los del mundo que lo hacen parecer un Reino al revés. No obstante, esto es solamente un asunto de perspectiva, pues el Reino, visto desde el mundo parece estar al revés. Pero si observásemos al mundo desde el Reino, sería el mundo el que en verdad se encuentra al revés.

No se puede entender la realidad cuando la misma está siendo observada al revés. En un país europeo se hizo la exposición de una pintura de arte moderno. Durante

1 Kraybill, Donald B. El Reino al revés. Ediciones ClaraSemilla. Colombia-Guatemala, 1995. varios días la pintura recibió elogios de diversos críticos, hasta que el autor de la obra se hizo presente en la sala de exposiciones. Inmediatamente expresó su molestia a causa que su obra había sido colocada de manera invertida. Los críticos que habían expresado sus opiniones 'eruditas' sobre la obra no fueron capaces de advertir que la pintura se encontraba al revés.

El entender la realidad se vuelve todo un desafío cuando no tenemos la perspectiva correcta de ella. Solamente desde los valores del Reino de Dios podremos contar con los elementos necesarios y suficientes para entender la realidad mundana que se encuentra al revés. Solamente cuando entendamos que la dicha no está en el reír sino en el llorar, no en el hartazgo sino en el hambre, no en la riqueza sino en la pobreza, no en la popularidad sino en la persecución, podremos entender correctamente la realidad.

1.2. Porque creemos que la realidad no incumbe al cristiano. Mientras se continúe pensando que la Iglesia debe ocuparse solamente de las cosas 'espirituales', encontraremos un enorme obstáculo para entender la realidad. La no confesión del señorío de Jesús sobre toda su creación es 
una falta que llevará a la Iglesia a encerrarse en su pequeño mundo, pensando que todos aquellos elementos extra eclesiales no son de su incumbencia.

Quien cree que el Evangelio no tiene nada que ver con la realidad, todavía no sabe nada sobre lo que el Evangelio es. El cristianismo nació a partir de un ser histórico, Jesús, quien vivió en una realidad que perfectamente puede ser definida de manera geográfica, histórica, social, económica y política. Esa realidad influyó en lo que Jesús era, dijo e hizo. De igual manera, todo lo que Jesús fue, dijo e hizo ejerció poderosa influencia sobre esa realidad. Lo más notable de todo es que Jesús siempre adoptó una postura frente a su realidad en todos sus ámbitos. Desde entonces, el modelo de Jesús es un paradigma permanente para la Iglesia. El cristianismo solamente puede ser fiel a su razón de ser cuando adopta la postura rectora de Jesús ante su realidad particular.

"En los inicios del régimen hitleriano un joven teólogo alemán comenzó a preocuparse por las inquietantes señales de injusticia y desorden social que observaba. Buscaba a amigos y parientes, algunos de ellos con puestos importantes dentro del gobierno nazi, para que le aclararan la realidad de lo que estaba pasando en su patria. Todos respondían evasivamente y algunos le contestaban: "Es mejor no saber". El consejo era no meterse en líos y no buscarse problemas. Pero reflexionando sobre lo que significaba ser discípulo de Jesucristo en la Alemania de Adolfo Hitler, ese joven, Dietrich Bonhoeffer, llegó a otra conclusión: un cristiano tiene que saber. Bonhoeffer sabía que para ser fiel a su Señor, tenía que entender bien la realidad de su mundo y sus males." ${ }^{2}$

2 Stam, Juan. Apocalipsis y profecía. Ediciones Kairós. Buenos Aires. 2004. Pág. 9 .
Porque nuestra visión está nublada. Hay diversos elementos que nublan la visión de la realidad del cristiano. Consideremos algunos de esos elementos:

La falta de información. No se puede ser fiel a la pertinencia del mensaje evangélicosinoposeemoslainformación adecuada acerca de la realidad que nos envuelve. Spurgeon expresó en cierta ocasión que los ministros del evangelio debían predicar con una Biblia en una mano y el periódico en la otra. Pocas cosas hay tan penosas como escuchar a un cristiano pontificar desde una posición de ignorancia sobre la realidad presente.

La versión de los medios de comunicación. El cristiano no tiene un contacto directo con la realidad, solamente lo tiene con la versión que de la realidad le presentan los medios. Para nadie es un secreto que los medios de comunicación distan mucho de ser objetivos e imparciales en la presentación de la realidad. Lo que normalmente tenemos es una interpretación ya elaborada de la realidad.

No hay otro camino para sobreponerse a la visión nublada de la realidad que los medios nos ofrecen que el 'andar' la realidad. El cristiano tiene la obligación de andar la vida, andar por los campos, andar por las calles, andar con lo pobres a fin de conocer la realidad sin modificaciones. $^{3}$

\footnotetext{
3 "La solidaridad con los marginados, más que un interesante discurso teológico o una relevante propuesta ideológica, tiene que ser una experiencia cotidiana que descanse en el riesgo de identificarse públicamente con los sectores social y culturalmente marginados. Consecuentemente, sentarse en la misma mesa y partir el pan en comunión con los desheredados de este mundo forma parte de un estilo misionero que tiene como punto de partida un encuentro con el prójimo en algún tramo del camino. En consecuencia, los cinco principios que moldean la cadena inquebrantable del amor-entrega:
} 
Por la acción de la política partidista. En un ambiente con fuerte carga de política partidista se dificulta la visión de la realidad debido a que las maquinarias publicitarias partidistas presentan sus particulares versiones de las cosas. Aunque resulta difícil sustraerse de la influencia que la política partidaria ejerce en la visión de la realidad, el cristiano posee el deber ético de investigar, documentar y conocer la realidad.

La política partidista es parte de la realidad. Pero no se debe cometer el error de visualizar toda la realidad desde el estrecho ángulo de la política partidista; es importante conservar la visión de conjunto, colocando las posiciones partidarias en el lugar que le corresponde.

\section{¿Por qué es un desafío confrontar la realidad?}

Confrontar es un paso adelante de entender la realidad. Entenderla supone acercarse a ella, investigarla y aprehenderla. Confrontar la realidad implica cuestionarla, detenerla, desafiarla, desviarla, transformarla. Estas tareas demandan incomodidad, trabajo, valentía, constancia, persecución. En una palabra, confrontar la realidad se vuelve un desafío pastoral porque requiere coraje.

Pero es precisamente coraje lo que Jesús entregó a su iglesia cuando prometió enviar el Espíritu Santo. El tema del Espíritu, Santo en cuanto a coraje para confrontar la realidad, es tan clave en este punto que vale

salir, ver, compasión, compromiso, transformación. Estos cinco principios, más que simples etapas de un proceso hermenéutico o una forma de caminar entre los pobres y los marginados, constituyen y jalonan un estilo de vida que reconoce en el otro, no a un objeto o cosa, sino a un sujeto con dignidad y derechos". López R., Darío. La misión liberadora de Jesús. Ediciones Puma. Lima. 2004. Págs. 42 y 43. la pena revisar lo que el libro de los Hechos de los Apóstoles nos dicen al respecto:

Estimado Teófilo, en mi primer libro me refería todo lo que Jesús comenzó a hacer y enseñar ${ }^{2}$ hasta el día en que fue llevado al cielo, luego de darles instrucciones por medio del Espíritu Santo a los apóstoles que había escogido. ${ }^{3}$ Después de padecer la muerte, se les presentó dándoles muchas pruebas convincentes de que estaba vivo. Durante cuarenta días se les apareció y les habló acerca del reino de Dios. ${ }^{4}$ Una vez, mientras comía con ellos, les ordenó: -No se alejen de Jerusalén, sino esperen la promesa del Padre, de la cual les he hablado: ${ }^{5}$ Juan bautizó con agua, pero dentro de pocos días ustedes serán bautizados con el Espíritu Santo. ${ }^{6}$ Entonces los que estaban reunidos con él le preguntaron:-Señor, ¿es ahora cuando vas a restablecer el reino a Israel?

${ }^{7}$ - No les toca a ustedes conocer la hora ni el momento determinados por la autoridad misma del Padre -les contestó Jesús-. ${ }^{8}$ Pero cuando venga el Espíritu Santo sobre ustedes, recibirán poder y serán mis testigos tanto en Jerusalén como en toda Judea y Samaria, y hasta los confines de la tierra.

${ }^{9}$ Habiendo dicho ésto, mientras ellos lo miraban, fue llevado a las alturas hasta que una nube lo ocultó de su vista. ${ }^{10}$ Ellos se quedaron mirando fijamente al cielo mientras él se alejaba. De repente, se les acercaron dos hombres vestidos de blanco, que les dijeron: 11 _ Galileos, ¿qué hacen aquí mirando al cielo? Este mismo Jesús, que ha sido llevado de entre ustedes al cielo, vendrá otra vez de la misma manera que lo han visto irse. ${ }^{4}$

4 Hechos 1:1-11 (NVI). 
De este pasaje se pueden señalar los siguientes elementos en torno al tema de confrontar la realidad.

El Reino de Dios y el Espíritu Santo prometido. En los primeros cinco versículos de Hechos capítulo uno, se nos enseña que Jesús una vez resucitado 'les habló acerca del Reino de Dios'. Lucas, en su primer tratado, establece que el mensaje central de Jesús fue el anuncio del Reino de Dios. Jesús nació como rey, Herodes trató de asesinarlo sabiendo que el nacimiento de un rey de los judíos constituía una amenaza a su posición de poder. Jesús predicó del Reino de Dios, anunció quiénes son sus ciudadanos, quiénes entran en él, los valores que le rigen, manifestó las señales del Reino y anunció su venida para la consolidación plena de su Reino universal.

Se ha dicho que Jesús vino para presentar el Reino de Dios a Israel; pero cuando éste lo rechazó, Dios retiró su mensaje del Reino y lo cambió por el mensaje del evangelio, postergando el anuncio del Reino para tiempos futuros. ${ }^{5}$ Pero, tal interpretación no es consistente con lo que Lucas relata que Jesús hizo al resucitar y fue el continuar enseñando sobre el Reino de Dios. No hubo tal cambio de planes. La enseñanza de Jesús sobre el Reino fue la misma antes de su muerte y después de su resurrección. Los discípulos así lo entendieron, pues el libro de los Hechos certifica que la Iglesia se dedicó no solamente a enseñar sobre el Reino de los cielos, sino también a vivir de acuerdo a sus valores.

Siguiendo vigente la confrontación que Jesús hizo de la realidad pecaminosa y la

5 "El nuevo mensaje de Jesús. El Rey se vuelve de la nación que lo ha rechazado, y ofrece no el reino, sino descanso y servicio a aquellos entre la nación que son conscientes de su necesidad espiritual. Este es un momento decisivo en el ministerio de Cristo". Scofield, C. I. Biblia anotada de Scofield. Publicaciones Españolas. Estados Unidos. 1977. Comentario a Mateo 11:28. acción de la iglesia para transformarla, la promesa del Espíritu Santo se muestra esencialmente vinculada al anuncio del Reino de Dios. La espiritualidad y manifestación del Espíritu, en su dimensión más definitiva, solo pueden ser entendidas a la luz del poder de Dios a favor del avance de su Reino.

El momento presente es uno cuando el misterio de iniquidad está operando y, al igual que en Janes y Jambres, lucha por desvirtuar la acción transformadora del Espíritu Santo, reduciendo su manifestación a expresiones anímicas y sensacionalistas que nada tienen que ver con aquella misión que el Padre le encomendó.

Esto no es nuevo. Ya en tiempos pasados Montano y sus seguidores se levantaron enseñando que el Espíritu había iniciado una época a la que llamaron 'la nueva profecía'. De esa manera interpretaba su momento como una era de visitación del Espíritu consistente en éxtasis, conmociones corporales, pretendidas profecías y otras muestras de fanatismo que llevaron a la Iglesia a condenar sus enseñanzas como herejía. ${ }^{6}$

El espíritu del montanismo es tan común hoy en día que amenaza seriamente a la Iglesia con perder la perspectiva de su misión: el anuncio del Reino de Dios. El Espíritu Santo es poder para transformar la realidad con la proclamación y la vivencia contundente del Reino de Dios y no el bufón divino y alienante que predicadores ególatras escenifican.

El poder del Espíritu y su consecuente espiritualidad se centran, pues, en dotar

6 "(Montano) y sus defensores afirmaban que su condición extática era señal de que estaba totalmente poseído del Espíritu Santo, quien estaba inaugurando una nueva dispensación de revelación divina”. Ferguson, Wright y Packer. Nuevo Diccionario de Teología, Casa Bautista de Publicaciones, El Paso, Tx. 1992. Pag. 647. 
a la Iglesia con el coraje necesario para confrontar la realidad a la manera de Jesús aun cuando tal cosa represente correr su mismo destino.

Los alcances del Reino de Dios. Los discípulos preguntaron a Jesús '¿es ahora cuando vas a restablecer el reino a Israel?' De acuerdo a la manera tradicional del pensamiento judío, los apóstoles veían el Reino de Dios como una exclusividad para el pueblo de Israel. Jesús colocó ante ellos una nueva frontera del Reino: 'Pero cuando venga el Espíritu Santo sobre ustedes, recibirán poder y serán mis testigos tanto en Jerusalén como en toda Judea y Samaria, y hasta los confines de la tierra.' El Reino no es solamente para Israel; es hasta para los confines de la tierra.

La Iglesia yerra cuando, al igual que los apóstoles, limita los alcances del Reino a la esfera de sus prácticas de culto. Al igual que en el modelo de Jesús, la vivencia del Reino de Dios debe extenderse a las áreas sociales, económicas, políticas y culturales de todas las naciones hasta los confines de la tierra. El poder del Espíritu sobre la Iglesia es la clave que garantiza el cumplimiento de su misión en todas las áreas de su realidad para transformarla.

El ser humano dignificado. Nuestro pasaje también menciona la ascensión de Jesús. Es frecuente en las predicaciones el tema de la crucifixión o el de la resurrección de Cristo. Pero, raras veces se escuchan exposiciones sobre su ascensión, aun cuando la misma es tan significativa para la redención como lo son los otros temas.

Lo que ascendió fue el cuerpo de Jesús. Lo que se encuentra a la diestra del Padre es un cuerpo humano glorificado. Tal verdad demuestra de la manera más convincente la dignidad de la corporeidad humana. Muy lejos de las concepciones victorianas, el cristianismo enseña la dignidad del cuerpo $y$, consecuentemente, justifica supremamente su preservación y cuidado. La Iglesia, apropiándose de esta verdad, debe incluir en su misión las acciones necesarias para asegurar la dignificación de todo ser humano creado a semejanza de Dios. Esta dignificación implica la consecución de todos aquellos elementos necesarios para que una persona posea vida plena.

La dirección de nuestra mirada. Los hombres vestidos de blanco dijeron a los discípulos: 'Galileos, ¿qué hacen aquí mirando al cielo? Este mismo Jesús, que ha sido llevado de entre ustedes al cielo, vendrá otra vez de la misma manera que lo han visto irse.' Era necesario corregir la dirección de la mirada. Mientras los discípulos veían ascender a Jesús, quizá anhelando partir con él, se les dijo que en lugar de ir ellos con Jesús al cielo, Jesús vendrá de regreso a la tierra. El Reino de Dios será establecido en la tierra. No es un Reino inmaterial o intangible. Será el establecimiento definitivo de la voluntad de Dios sobre el planeta.

La Iglesia pierde el sentido de su misión cuando adopta una actitud escapista evadiendo las complicaciones de su realidad bajo la idea que, finalmente, un día estará en el cielo. La voluntad de Dios señala en la dirección opuesta. Debemos dejar de ver al cielo para ir a la tierra a anunciar el Reino de Dios hasta sus confines. El signo de toda genuina espiritualidad reside en el compromiso del creyente con el Reino de Dios y su justicia, que con la llenura del Espíritu Santo, se convierte en un testigo que se opone al pecado individual y estructural que caracteriza la realidad mundana. 


\section{El compromiso pastoral}

Una vez establecidos los desafíos pastorales para entender y confrontar la realidad, es importante señalar algunos de los elementos que no deben faltar en el ideario pastoral en su deseo de ser fiel al compromiso que comporta ser un testigo de Cristo en medio de una realidad pecaminosa.

La muerte al yo. El primero de los elementos a vencer en la tarea pastoral es el pastor mismo. Jesús dijo que la única manera de seguirle es negándose a sí mismo. No existe nada más opuesto al Espíritu de Dios que el fomento de la imagen humana y la búsqueda de la popularidad y la fama por parte de los ministros. Tales cosas van en consonancia con los valores mundanos $y$, consecuentemente, se constituyen en elementos del anti-reino.

La mundanalización de la Iglesia. La Iglesia es muy cuidadosa de aquellos elementos considerados mundanos y que se expresan de la manera más escandalosa, como las borracheras, el adulterio, la drogadicción, etc. No obstante, existen otros elementos igualmente mundanos, pero que con mayor sutileza se introducen en la Iglesia sin que se advierta en la mayor parte de los casos. Un ejemplo de ello se produce cuando la Iglesia reproduce dentro de sí anti-valores como lo describe Santiago 2:

Hermanos míos, la fe que tienen en nuestro glorioso Señor Jesucristo no debe dar lugar a favoritismos. ${ }^{2}$ Supongamos que en el lugar donde se reúnen entra un hombre con anillo de oro y ropa elegante, y entra también un pobre desarrapado. ${ }^{3}$ Si atienden bien al que lleva ropa elegante y le dicen: "Siéntese usted aquí, en este lugar cómodo», pero al pobre le dicen: "Quédate ahí de pie» o «Siéntate en el suelo, a mis pies», ${ }^{4}$ ¿acaso no hacen discriminación entre ustedes, juzgando con malas intenciones?

${ }^{5}$ Escuchen, mis queridos hermanos: ¿No ha escogido Dios a los que son pobres según el mundo para que sean ricos en la fe y hereden el reino que prometió a quienes lo aman? ${ }^{6}$ iPero ustedes han menospreciado al pobre! ¿No son los ricos quienes los explotan a ustedes y los arrastran ante los tribunales? ${ }^{7}$ ¿No son ellos los que blasfeman el buen nombre de aquel a quien ustedes pertenecen?

Peca la Iglesia cuando privilegia a aquellos que el Señor no ha privilegiado y menosprecia a quienes él ha mostrado su amor preferente porque han creído para heredar el Reino. Dentro de la Iglesia las cosas deben estructurarse de manera tal que sean privilegiados los que afuera son menospreciados y se les otorgue un lugar de honor a aquellos que afuera no tienen lugar ninguno.

El Reino para todos. La práctica pastoral debe conducir a la proclamación del mensaje del Reino a todos y todas. El tema del Reino de Dios y su justicia no debe ser un tema privado de un pequeño círculo de teólogos sesudos. Debe ser la buena nueva que se anuncie públicamente y sin limitaciones. Todos y todas deben saber que el Reino de Dios ha llegado.

Imitar el modelo de Jesús. En su vida y enseñanzas, Jesús dejó indicado el camino que deben seguir todos aquellos que han tomado el nombre 
de cristianos. La Iglesia, como fiel seguidora y perpetuadora del modelo de Jesús, debe encarnar las posturas, preferencias y opciones que aquél adoptó en cuanto a temas sociales, políticos y económicos. Jesús vivió en un momento histórico concreto cuando la sociedad separaba a los seres humanos clasificándolos por segmentos. Pero no solamente vivió en una sociedad estratificada, sino que se encarnó en una de esas estratificaciones, vivió con ellos, los llamó bienaventurados y pronunció fuertes ayes contra los que les confinaban a tales condiciones. Jesús también se pronunció sobre cuestiones económicas que rompieron y rompen las lógicas financieras aceptadas comúnmente, para sustituirlas por otras que resultaron inverosímiles ayer $\mathrm{y}$ hoy. Todo ello, con consecuencias inevitablemente políticas que le condujeron a ser condenado a muerte como un opositor político. Veamos algunas de esas enseñanzas:

El salario mínimo. En la época de Jesús, al igual que ahora, regía la costumbre que las personas eran remuneradas de acuerdo a su grado de producción. A mayor producción mayor remuneración; y a menor producción, menor remuneración. Lo que se asegura es el margen de ganancia. No obstante, Jesús subvierte tal lógica de mercado y antepone la dignidad humana como el elemento fundamental que debe ser preservado sobre cualquier interés económico.

Mateo 20: Así mismo el reino de los cielos se parece a un propietario que salió de madrugada a contratar obreros para su viñedo. ${ }^{2}$ Acordó darles la paga de un día de trabajo y los envió a su viñedo. ${ }^{3}$ Cerca de las nueve de la mañana, salió y vio a otros que estaban desocupados en la plaza. ${ }^{4}$ Les dijo: "Vayan también ustedes a trabajar en mi viñedo, y les pagaré lo que sea justo." ${ }^{5}$ Así que fueron. Salió de nuevo a eso del mediodía y a la media tarde, e hizo lo mismo. ${ }^{6}$ Alrededor de las cinco de la tarde, salió y encontró a otros más que estaban sin trabajo. Les preguntó: "¿Por qué han estado aquí desocupados todo el día?" 7 "Porque nadie nos ha contratado", contestaron. Él les dijo: "Vayan también ustedes a trabajar en mi viñedo."

${ }^{8} \mathrm{Al}$ atardecer, el dueño del viñedo le ordenóasucapataz: "Llamaalosobreros y págales su jornal, comenzando por los últimos contratados hasta llegar a los primeros." 9 Se presentaron los obreros que habían sido contratados cerca de las cinco de la tarde, y cada uno recibió la paga de un día. ${ }^{10}$ Por eso cuando llegaron los que fueron contratados primero, esperaban que recibirían más. Pero cada uno de ellos recibió también la paga de un día. ${ }^{11} \mathrm{Al}$ recibirla, comenzaron a murmurar contra el propietario. 12 "Estos que fueron los últimos en ser contratados trabajaron una sola hora - dijeron-, y usted los ha tratado como a nosotros que hemos soportado el peso del trabajo y el calor del día." "13 Pero él le contestó a uno de ellos: "Amigo, no estoy cometiendo ninguna injusticia contigo. ¿Acaso no aceptaste trabajar por esa paga? ${ }^{14}$ Tómala y vete. Quiero darle al último obrero contratado lo mismo que te di a ti. ${ }^{15}$ ¿Es que no tengo derecho a hacer lo que quiera con mi dinero? ¿O te da envidia de que yo sea generoso?" 
16 "Así que los últimos serán primeros, y los primeros, últimos".

En esta parábola del Reino, Jesús parte de la usanza de su época. Cada campesino recibía un denario por una jornada de trabajo de doce, horas. El denario era considerado el salario mínimo, la paga de un día de trabajo. El salario mínimo era la manera de asegurar la subsistencia de la mano de obra. Con menos de un denario al día no podía asegurarse la subsistencia de una familia campesina promedio.

Cuando el propietario sale muy temprano a contratar labradores ofreciéndoles un denario por una jornada de doce horas, estaba actuando como era la costumbre de la época. El escándalo de la parábola se encuentra al final del día de trabajo, cuando el propietario paga el salario de un día de trabajo tanto a los que habían laborado las doce horas como a los que habían laborado nueve, seis, tres y una hora. La clave de toda la parábola se encuentra en las palabras del propietario a los que fueron contratados de las nueve de la mañana en adelante: 'Les pagaré lo que sea justo'. ¿Qué es lo justo? Lo justo desde la óptica de las leyes del mercado era que los que habían producido menos ganaran menos, pero lo justo desde la óptica del Reino de Dios era que cada uno recibiera lo necesario para la vida, aún cuando hubiese producido tan sólo por una hora. El valor supremo es la vida humana, por sobre todo interés económico. Esto escandalizó a los que escucharon a Jesús, principalmente a los propietarios de la tierra, y continuará escandalizando a los propietarios y empresarios del presente y del futuro.
Como Pastor, he enseñado ésto a la congregación. Un hermano, que ocupa una posición de gerencia media en una empresa, estaba impresionado al final de la enseñanza. Me manifestó su sorpresa ante los criterios de Jesús sobrela administración económica. No soy demasiado optimista como para pensar que con esa sola enseñanza la justicia pueda ser promovida en el campo laboral, solamente porque un gerente medio de una sola empresa se muestre convencido del modelo de Jesús; pero tampoco soy demasiado pesimista como para no creer que la repetida enseñanza de los valores del Reino de Dios no habrá de terminar calando hasta lograr transformar la injusta realidad económica de nuestros países.

La acción política. Aunque Jesús no militó en ninguno de los partidos políticos de su época, es innegable que ejerció una fuerte influencia política sobre su realidad. Su proclama del Reino de Dios denunció la injusticia y el pecado, desenmascaró a las élites opresoras y condenó a los avaros inmisericordes. Tales anuncios y denuncias incidieron en los campos religiosos, laborales y sociales. Su proclama no fue la toma del poder, sino la transformación de esas relaciones dentro de su realidad.

'A los pobres, marginados y vulnerables Jesús les ofrece ejemplos y estrategias de cómo enfrentarse a los poderosos. Jesús no apela ni a la violencia ni a la pasividad, sino a la resistencia no violenta. A los pobres no les dicta leyes ni modelos de acción, sino sugerencias creativas.?

7 Sánchez Cetina, Edesio. ¿Qué es la Biblia? Respuestas desde las ciencias bíblicas, Ediciones Kairós, Buenos 
Los discípulos de Jesús asimilaron sus enseñanzas sobre la no violencia y las utilizaron cuando llegó su turno de chocar contra el status quo en su praxis misional. En Hechos capítulo 4, encontramos a la élite religiosa ordenando a los Apóstoles 'terminantemente que dejaran de hablar y enseñar acerca del nombre de Jesús' (Versículo 18). La respuesta de los discípulos fue igualmente categórica: ¿¿Es justo delante de Dios obedecerlos a ustedes en vez de obedecerlo a él? ¡Júzguenlo ustedes mismos! Nosotros no podemos dejar de hablar de lo que hemos visto y oído' (Versículos 19 y 20). Los Apóstoles se negaron a obedecer una ordenanza injusta.

Henry David Thoreau escribiría siglos después su concepto de la Desobediencia Civil, la cual definió como una desobediencia consciente, voluntaria y pública a una ley injusta, que implica la disposición de aceptar el castigo o pena que tal desobediencia pueda ocasionar. Mucho antes de Thoreau, los Apóstoles aplicaron el principio de la desobediencia civil como herramienta de acción política a fin de oponerse de manera no violenta a una situación injusta. Tiempo después, Mohandas Karamchad Gandhi retomaría el concepto de la desobediencia civil, unido al de la no violencia, para obtener resultados sorprendentes de una nueva manera de hacer política y que demostraría que las enseñanzas de Jesús son totalmente válidas y efectivas. Para vergüenza de la Iglesia, no fue un cristiano quien lo demostró, sino un hinduista. No obstante, el campo está abierto para el momento cuando un
Pastor cristiano obediente decida transformar las relaciones que tejen la realidad con el poder del evangelio, del Espíritu, de la justicia y de la verdad.

Un episodio dramático del método de la lucha no violenta de Gandhi se produjo cuando aconsejó la desobediencia civil ante el injusto impuesto sobre la sal que los británicos establecieron a la población de la India. En abril de 1930, Gandhi culminó la 'marcha de la sal' violando la arbitraria ley inglesa al recoger sal directamente del mar. $\mathrm{Su}$ acto animó a los campesinos pobres a seguir su ejemplo de desobediencia en todas las costas de la India. En las semanas siguientes anunció a la autoridad británica una nueva marcha hacia las salinas de Dharsana. Gandhi fue encarcelado antes de poder emprenderla; pero su discípula Naidu la encabezó en su lugar, seguida por más de dos mil quinientas personas. Los ingleses montaron guardia para impedirles el paso a golpes. Pero los discípulos de Gandhi continuaron marchando; y aunque les golpearon salvajemente, no respondieron a los golpes y siguieron marchando mostrando su fuerza moral. Por varias horas la policía inglesa debió golpear uno a uno a los miles de marchantes, mientras la prensa internacional tomaba nota de lo que estaba sucediendo. Los indios demostraron que las leyes inglesas ya no les alcanzaban. Ninguno de los participantes en la marcha logró ni siquiera tocar la sal, pero su desobediencia civil logró desarticular el poderío del imperio británico en la India. Posteriormente, los británicos, 
derrotados moralmente, otorgaron la independencia a la India. ${ }^{8}$

Aunque la desobediencia civil de los apóstoles no promovió, en ese momento, la transformación de las leyes injustas, al menos, sí mostró la manera de hacer efectivas las enseñanzas de Jesús sobre la no violencia y la desobediencia civil. Gandhi y Luther King Jr. mostraron que las transformaciones son posibles.

\section{Conclusión}

La Iglesia no podrá hacer sentir su presencia transformadora de la realidad mientras no experimente una vivencia profunda de los valores del Reino de Dios, los cuales, pasan por reconocer a la Iglesia como Cuerpo de Cristo. Desde esta perspectiva la Iglesia solamente cumplirá su mandato misional cuando reconozca que ninguna congregación particular, por numerosa que sea, podrá por sí sola cumplir la tarea del anuncio del Reino de Dios. Tal comprensión debe conducir a reconocer a todos los miembros del Cuerpo con sus dones, matices y gracias distintivas para que en un esfuerzo respetuoso puedan mostrar al mundo que son uno.

8 Aunque suele tildarse a la lucha no violenta y a la desobediencia civil como metodologías idealistasutópicas, los ejemplos concretos se multiplican en la historia. El Salvador tiene su propio modelo triunfante de desobediencia civil. Véase Insurrección no violenta en El Salvador, la caída de Maximiliano Hernández Martínez. Parkman, Patricia. Biblioteca de Historia Salvadoreña. Tomo 13, Dirección de Publicaciones e Impresos. San Salvador. 2006. La autora elabora una investigación histórica sobre la lucha no violenta, en mayo de 1944, que condujo a la renuncia del dictador General Maximiliano Hernández Martínez que se aferraba al poder de su cuarto período presidencial.
Dijo Soren Kierkegaard: 'Mientras que Cristo cambió el agua en vino la iglesia ha tenido éxito en hacer algo más difícil: ha cambiado el vino en agua.' Quiera Dios ayudarnos para ser fieles a su programa del Reino y que tengamos la valentía necesaria para conservar el vino como vino, tal como Jesús lo dejó. 